\title{
STUDI ETNOGRAFI PERSEPSI KAUM PRIA DI WILAYAH PESISIR KEC.ABELI KOTA KENDARI MENGENAI KB PRIA/VASEKTOMI
}

\author{
Jumartin Gerung ${ }^{1}$ Ridia Utami Kasih ${ }^{2}$ \\ ${ }^{1,2}$ Program Studi Kesehatan Masyarakat, STIKES Mandala Waluya, Kendari \\ jumartin.gerung@gmail.com
}

\begin{abstract}
Abstrak
Penelitian mengenai vasektomi ini ini bertujuan untuk mempelajari dan memberikan gambaran tentang pengaruh budaya, filosofi hidup atau kepercayaan, dukungan sosial serta faktor ekonomi terhadap keikutsertaan suami dalam metode kontrasepsi vasektomi. Penelitian ini dilakukan secara kualitatif dengan desain etnografi yakni metode penelitian yang dilaksanakan melalui pendekatan budaya. Penelitian dilakukan melalui wawancara mendalam kepada informan biasa dan informan kunci. Informan dipilih dengan teknik snow ball sampling dengan pertimbangan bahwa pencarian sampel dihentikan jika telah mendapatkan informasi yang cukup melalui triangulasi metode. Hasil wawancara disusun secara taksonomi lalu disusun dalam bentuk narasi. Hasil penelitian menunjukkan persepsi mengenai vasektomi dipengaruhi oleh pengetahuan umum terkait program KB. Jadi dari sisi budaya maupun kepercayaan masih didominasi permasalahan pengaturan anak boleh, namun untuk pembatasan jumlah anak dinilai bertentangan dengan filosofi hidup masyarakat. Adapun masalah Vasektomi beberapa informan menyatakan bahwa pengetahuan mereka mengenai vasektomi masih sangat minim. Bahkan ada yang belum mengetahui terkait dengan KB pria. Ketakutan akan operasi vasektomi yang permanen juga menguatkan alasan, mengapa kaum pria di wilayah Abeli belum mau ber-KB. Informan kunci mengungkapkan bahwa cakupan edukasi terkait vasektomi masih sangat kurang. Dibutuhkan upaya promosi jika cakupan akseptor kontrasepsi pria melalui vasektomi ini ingin ditingkatkan.
\end{abstract}

Kata Kunci : Etnografi dan Vasektomi

\begin{abstract}
Research on vasectomy aims to identify and provide an overview of the influence of culture, philosophy of life or beliefs, social support and economic factors on husband participation in the vasectomy contraceptive method. This research was conducted qualitatively with an ethnographic design, namely the research method carried out through a cultural approach. The research was conducted through in-depth interviews with regular informants and key informants. Informants were selected using the snow ball sampling technique with the consideration that the sample search was stopped if sufficient information was obtained through method triangulation. The results of the interviews were compiled taxonomically and then described in a narrative form. The results showed that perceptions about vasectomy were influenced by general knowledge regarding the family planning program. In terms of culture and belief, the problem of regulating children is still dominated, but limiting the number of children is considered contrary to the philosophy of life of the community. As for the problem of vasectomy, some informants stated that their knowledge about vasectomy is still very minimal. There are even those who do not know about male family planning. The fear of a permanent vasectomy also reinforces the reason why men in the Abeli area do not want to have family planning. Key informants revealed that the education coverage related to vasectomy was still lacking. Promotional efforts are needed if the coverage of male contraceptive acceptors through vasectomy is to be increased.
\end{abstract}

Keywords: Ethnography and Vasectomy 


\section{PENDAHULUAN}

Vasektomi adalah kontrasepsi bedah untuk pria dengan cara memutus saluran spermanya. Lelaki yang melakukan vasektomi secara permanen tidak bisa menghamili perempuan sehingga kerap dicurigai mudah berselingkuh. Saat ini, hanya sekitar 0,09 persen dari 7,6 juta peserta program Keluarga Berencana (KB) di Indonesia yang menggunakan metode vasektomi. Data Badan Kependudukan dan Keluarga Berencana Nasional (BKKBN) ini menguatkan pesan, bahwa kaum pria di Indonesia belum mau ber-KB.

Badan Kependudukan dan Keluarga Berencana Nasional (BKKBN) Sulawesi Tenggara menyebutkan peminat KB dengan sistem metode operasi pria (MOP) atau vasektomi pada 2017 sebanyak 26 orang. Kepala Bidang Advokasi Pergerakan dan Informasi (Adpin) BKKBN Sultra, Agus Salim,mengungkapkan peminat tersebut masih tergolong rendah jika dibanding dengan target.

Dari target 123 orang pesrta KB pria (vasektomi) tahun 2017, yang terealisasi hanya 26 orang atau 21,14 persen. Dari 17 kabupaten kota di Sultra, hanya terdapat lima daerah yang berhasil menggaet peserta KB baru pria atau metode vasektomi. Lima daerah itu adalah Kabupaten Konawe tiga orang, Kabupaten Muna 10 orang, Kolaka Timur tiga orang, Buton Tengah empat orang dan Kota Kendari enam orang. Persepsi bahwa masalah KB merupakan urusan perempuan memang belum begitu di eksplor di kalangan masyarakat. Padahal sebenarnya pria dapat berperan dalam program KB melalui $\mathrm{MOP}^{(1)}$

Vasektomi dikenal dengan istilah medis operasi pria (MOP) merupakan salah satu metode kontrasepsi efektif. Menurut BKKBN, kontrasepsi melalui vasektomi memiliki efek samping yang kecil, tingkat kegagalan juga sangat kecil dan berjangka panjang. Vasektomi adalah kontrasepsi bedah untuk pria dengan cara memutus saluran spermanya. Lelaki yang melakukan vasektomi secara permanen tidak bisa menghamili perempuan sehingga kerap dicurigai mudah berselingkuh.

Operasi vasektomi menghambat saluran spermatozoa (vas deferens) yang membawa sperma keluar. Operasi ini biasanya dilakukan di klinik atau rumah sakit dengan melibatkan pemotongan dan mengikat mati (cauterizing) saluran sperma. Namun karena operasi kontrasepsi ini bersifat permanen, maka pria yang ingin melakukannya harus sudah benar-benar yakin tidak ingin memiliki anak lagi dan tidak akan berubah pikiran ${ }^{(2)}$.
Pria yang sudah melakukan vasektomi masih terus memproduksi sel benih yang diproduksi buah zakar. Hanya saja karena salurannya diputus tidak bisa keluar bersama ejakulasi. Sel-sel benih itu akan diserap lagi oleh tubuh dan tidak membahayakan kesehatan. Vasektomi juga tidak mempengaruhi hormon testosteron. Ada beberapa keuntungan dan kerugian dari kontrasepsi vasektomi yakni :

\section{Keuntungan}

1. Vasektomi adalah operasi kecil yang aman, sangat efektif dan bersifat permanen.

2. Baik dilakukan pada laki-laki yang memang sudah tidak ingin memiliki anak.

3. Vasektomi lebih murah dan lebih sedikit komplikasi dibandingkan dengan sterilisasi tuba.

4. Pria memiliki kesempatan untuk gantian KB dengan istrinya.

5. Tidak mempengaruhi kemampuan seorang pria dalam menikmati hubungan seksual.

\section{Kerugian}

1. Beberapa laki-laki takut vasektomi ini akan mempengaruhi kemampuannya berhubungan intim atau menyebabkan gangguan ereksi.

2. Ada sedikit rasa sakit dan ketidaknyaman beberapa hari setelah operasi, rasa sakit ini biasanya bisa hilang dengan konsumsi obat ringan.

3. Seringkali harus melakukan kompres dengan es selama 4 jam untuk mengurangi pembengkakan, pendarahan dan rasa tak nyaman serta harus memakai celana yang dapat mendukung skrotum selama 2 hari.

4. Operasi tidak efektif dengan segera. Pasien diharuskan memakai kondom terlebih dahulu untuk membersihkan tabung dari sisa sperma yang ada. Untuk mengetahui sudah steril atau belum, biasanya dilakukan pemeriksaan mikroskop setelah 20-30 kali ejakulasi.

5. Vasektomi tidak memberikan perlindungan terhadap infeksi seksual menular termasuk HIV.

6. Penyesalan setelah vasektomi lebih besar jika laki-laki masih berusia di bawah 25 tahun, terjadi perceraian atau ada anaknya yang meninggal.

7. Dibutuhkan waktu 1-3 tahun untuk benar-benar memastikan apakah vasektomi bisa bekerja efektif 100 persen atau tidak.

Saat ini, hanya 0,09 persen dari 7,6 juta peserta program Keluarga Berencana (KB) di Indonesia yang menggunakan metode vasektomi. Data Badan Kependudukan dan Keluarga Berencana Nasional (BKKBN) ini menguatkan pesan, bahwa kaum pria di Indonesia belum mau ber-KB. 
Di Amerika Latin termasuk Meksiko, kriteria orang yang melakukan vasektomi adalah sebagai berikut (1) berusia lebih dari 30 tahun (2) memiliki jumlah anak tiga atau lebih (3) tinggal didaerah perkotaan (4) sebelum menggunakan metode vasektomi mereka sudah menggunakan metode KB yang lain (5) memiliki tingkat pendidikan yang lebih tinggi dari rata-rata nasional.

Di India, hal pertama kali yang dilakukan oleh dokter-dokter bedah sebelum dilakukannya operasi tubektomi adalah memberi motivasi kepada pasien tentang pentingnya tubektomi bagi keluarga berencana. Sebagian besar peserta yang menjalani tubektomi adalah yang memiliki 3 sampai 4 anak. Semua peserta tubektomi yang telah menjalani operasi menerima insentif ekonomi sebagai kebijakan pemerintah setelah operasi, hampir semua mengatakan bahwa uang yang diterima dihabiskan sebagai uang transportasi dan pengobatan. Sebenarnya sebagian besar peserta menegaskan bahwa mereka akan memilih untuk operasi bahkan tanpa adanya insentif keuangan seperti itu untuk kebaikan mereka sendiri.

Di Cina Kebijakan negara "membatasi jumlah populasi dan meningkatkan kualitas populasi" (Chen Muhua, 1986) adalah panduan untuk membentuk kebijakan kesuburan lokal. Menurut peraturan provinsi tentang perencanaan kelahiran saat ini, Pemerintah mengadvokasi pernikahan yang terlambat, terlambat melahirkan. dan setiap pasangan hanya memiliki satu anak. Anak kedua hanya diijinkan untuk pasangan yang masuk dalam kategori tertentu $\mathrm{Di}$ Cina metode sterilisasi telah digunakan sebanyak 30\% dari kontrasepsi yang ada. Menurut data yang diteliti, jumlah pemakaian tubektomi sebanyak $20.3 \quad$ juta dan 13,8 juta untuk vasektomi data ini diambil pada tahun 1971 dan 1978.

Informasi tentang vasektomi sangat kurang. Vasektomi lebih banyak dilakukan pria dari kalangan ekonomi menengah-bawah yang punya anak banyak dan tak ingin punya anak lagi. Adapun di Malaysia, Banglades, dan Pakistan, vasektomi dikenalkan sejak lama. Di Indonesia sendiri cakupan akseptor vasektomi dalam program KB masih rendah secara nasional. Beberapa faktor yang dapat memengaruhi tingginya cakupan vasektomi diantaranya nilai budaya, kepercayaan, dan sosial ekonomi. $^{(3)}$

Upaya promosi kesehatan melalui pelaksanaan strategi promosi kesehatan dapat menjadi alternatif untuk melakukan edukasi dan menyebarkan informasi kesehatan kepada masyarakat. Dalam upaya melakukan pendekatan dengan masyarakat, petugas kesehatan dapat membentuk kemitraan bersama para tokoh masyarakat maupun tokoh agama. (4)

Berdasarkan latar belakang tersebut, maka penelitian ini dilaksanakan untuk mengetahui persepsi kaum pria di wilayah pesisir kecamatan Abeli mengenai vasektomi/KB pria melalui studi etnografi.

\section{METODE}

Penelitian ini merupakan penelitian kualitatif dengan pendekatan etnografi, yang menggali dan mengkaji informasi tentang persepsi masyarakat yang berhubungan dengan masalah KB Pria/Vasektomi. Penelitian kualitatif ini dilakukan agar dapat diperoleh deskripsi dan konklusi yang kaya tentang konteks yang diteliti serta memahami makna yang mendasari tingkah laku dari masyarakat berdasarkan sudut pandang budaya, nilai, kepercayaan juga ekonomi.

\section{Lokasi dan Waktu}

Penelitian dilaksanakan di wilayah kecamatan Abeli khususnya di daerah Lapulu wilayah pesisir Abeli. Penelitian ini dilaksanakan dari bulan mei hingga agustus 2020.

\section{Informan Penelitian}

Informan dalam penelitian ini terdiri atas informan biasa dan informan kunci. Dimana informan biasa terdiri dari pria yang telah menikah dan berdomisili di wilayah kecamatan Abeli. Sedangkan informan kunci terdiri atas tokoh adat. Tokoh agama, dan para kader kesehatan. Informan dipilih dengan cara snowball sampling dengan pertimbangan bahwa jika informasi telah dinyatakan cukup, maka wawancara tidak dilanjutkan lagi.

\section{Metode Pengumpulan Data}

Pengumpulan data primer dilakukan melalui teknik Focus Group Discussion (FGD) yang dilakukan oleh peneliti yang dibantu oleh tenaga yang sudah dilatih (enumerator) selanjutnya untuk triangulasi data dilakukan pula diskusi dan indepth interview terhadap informan kunci yang terkait dengan tujuan penelitian. Pemilihan informan didasarkan atas kaidah yang berlaku dalam metode penelitian kualitatif yaitu kesesuaian (appropriateness) dan kecukupan (adequacy). Dengan pertimbangan kaidah tersebut maka yang ditetapkan sebagai informan biasa 7 orang Laki-laki yang telah menikah dan memiliki anak, sedangkan Informan kunci adalah kelompok tokoh masyarakat (toga dan toma), dan kader kesehatan sebanyak 3 orang. 


\section{Instrumen Penelitian}

Perlengkapan yang dipakai dalam riset ini ialah mp4 recorder, kamera, pedoman wawancara, dan alat tulis.

Prosedur Penelitian

FGD

Sebelum melakukan penelitian, terlebih dahulu dilakukan Focus Grup Discussion. Hal ini bertujuan untuk melakukan brain storming pada beberapa informan biasa. Dalam FGD ini sejumlah informan mengeluarkan pendapat terkait masalah vasektomi/KB pria. Selain itu, melalui FGD ini dapat diukur sejauh mana pengetahuan awal informan terkait vasektomi.

\section{Indepth Interview}

Indepth interview atau wawancara mendalam dilakukan baik pada informan biasa maupun pada informan kunci. Pada Informan biasa disampaikan pertanyaan terkait seputar pengetahuan masalah vasektomi, persepsi mereka mengenai vasektomi, vasektomi perspektif budaya, nilai, kepercayaan maupun masalah ekonomi dan agama.

Sedangkan kepada informan kunci yang terdiri dari kader kesehatan, tokoh adat dan tokoh agama disampaikan pertanyaan yang berbeda antara lain terkait proses edukasi yang dilakukan selama ini mengenai vasektomi, hambatan dan tantangan yang ditemukan di masyarakat, bagaimana adat dan budaya memandang masalah keluarga berencana, termasuk sudut pandang agama terkait masalah vasektomi.

\section{Analisis data}

Analisis data dalam penelitian ini menggunakan model analisis interaktif dalam penelitian kualitatif, analisis data dilakukan sejak awal penelitian dan selama proses penelitian dilaksanakan. Data diperoleh, kemudian dikumpulkan untuk diolah secara sistematis. Dimulai dari wawancara, observasi, mengedit, dan mengklasifikasi yang dapat digambarkan sebagai berikut (5) :

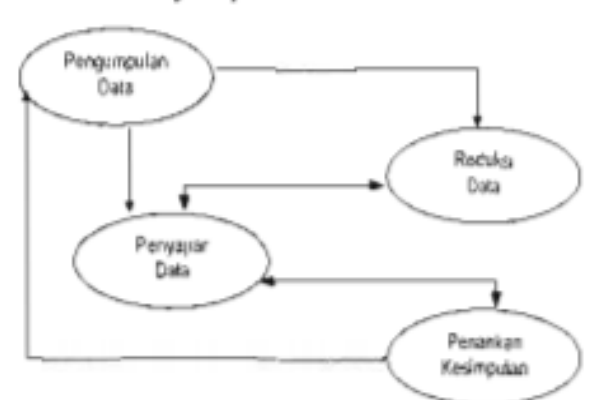

Gambar I. Analisis Data Model Interaktif Sumber: Miles dan Huberman (1984)

\section{HASIL}

Riset ini dilaksanakan secara kualitatif di wilayah kecamatan Abeli Kota Kendari. Dari hasil wawancara yang dilakukan terhadap informan kunci dan biasa, dapat dipaparkan bahwa kuatnya kontrol budaya terhadap kondisi kehidupan sehari-hari, mempengaruhi aspek psikologi masyarat penganut kebudayaan tersebut. Dalam pemilihan tindakan kesehatan pun sedikit banyak di pengaruhi oleh nilai, kepercayaan, dan adat istiadat masyarakat.

\section{Pengetahuan Mengenai Vasektomi}

Terkait dengan vasektomi, beberapa respon para informan menyatakan bahwa pengetahuan mereka mengenai vasektomi masih sangat minim. Bahkan ada yang belum mengetahui terkait dengan KB pria tersebut sebagaimana dalam kutipan wawancara berikut :

"KB yang saya tahu selama ini hanya sama perempuan saja...." (Am, 42 tahun)

"Belum begitu tau juga tentang itu..." (RG, 45 tahun)

"Ada...pernah dengar tapi nda terlalu tahu..." (SN, 39 tahun)

"Kalau masalah KB tau, kalau KB pria kayaknya baru juga itu ya..(KL, 40 tahun)

Meski demikian ada juga beberapa yang mengetahui mengenai vasektomi melalui informasi media dan pembicaraan di masyarakat

"tau, pernah dengar cerita-cerita.....(DG,

42 tahun)

Perspektif Budaya Mengenai Vasektomi

Budaya merupakan salah satu bagian yang tak terpisahkan dalam menentukan perilaku masyarakat.(6) Mengenai ada tidaknya hubungan antara budaya yang mempengaruhi persepsi mereka mengenai masalah KB pria ini kurang lebih sama dengan bagaimana masyarakat menyikapi masalah program keluarga berencana yang telah dicanangkan pemerintah selama ini.

"Masalah anak kan urusan Allah, rezeki sudah ada yang atur...." (SN, 39 tahun) 
"Sebenarnya kalau masalah pengaturan jarak, bagus itu karena kita juga ndak terlalu bagus pendapatan, tapi ya semua memang harus dilihat juga..." (DG, 42 tahun)

"Kalau menikah kita masih muda memang bagusnya itu KB memang. Tapi kalau seperti KB pria itu harus kita pelajari dulu...(RG, 45 tahun)

Adapun terkait persepsi dari sudut pandang budaya menunjukkan integrasi program KB pria belum begitu masif di kalangan masyarakat sehingga pengaruh budaya masih dipandang sama dengan program KB yang bertujuan untuk menjaga jarak kelahiran yang selama ini dijalani kaum Ibu.

"Kurang tau juga kalau hubungannya dengan masalah adat atau agama, kepercayaan itu Bu... (BD, 40 tahun)

"Kurangtau kalau masalah adat hanya saja kan kalau masalah KB lebih ke ibu-ibu... (AM, 42 tahun)

"Masalah anak kan urusan Allah, rezeki sudah ada yang atur....(RG, 45 tahun)

"Sebenarnya kalau masalah pengaturan jarak, bagus itu karena kita juga ndak terlalu bagus pendapatan, tapi ya semua memang harus dilihat juga....(KL, 40 tahun)

Saat dikonfirmasi ke pemuka adat sendiri terlihat bahwa terkait persepsi mengenai masalah vasektomi ini lebih dilihat sebagaimana KB pada umumnya sehingga dari sudut pandang budaya sekadar dilihat sebagai upaya untuk menjaga jarak kelahiran anak.

" Kalau masalah adat sebenarnya tidak ada yang spesifik mengatur masalah itu ya (vasektomi), tapi kalau masalah jaga jarak lahir ya itu seiring perkembangan jaman sudah jadi pemahaman bersama di masyarakat.....(SDK, tokoh masyarakat, 56 tahun)

Terkait pandangan mereka mengenai masalah KB pria itu sendiri terlihat adanya keraguan khususnya untuk kesehatan pria sendiri.

"Kalau menikah kita masih muda memang bagusnya itu KB memang. Tapi kalau seperti KB pria itu harus kita pelajari dulu....

"Kalau seperti yang saya diberi tahu tadi, takut-takut juga kita ...."

\section{Perspektif Agama}

Operasi vasektomi dilakukan untuk menghambat saluran spermatozoa (vas deferens) yang membawa sperma keluar. Operasi ini biasanya dilakukan di klinik atau rumah sakit dengan melibatkan pemotongan dan mengikat mati (cauterizing) saluran sperma. Hal tersebut dipandang oelh informan seperti kebiri.

"kalau seperti itu modelnya, kayak kebiri begitu berarti..." (Am, 42 th)

Saat dikonfirmasi ke pemuka agama terkait persepsi tersebut dijelaskan sebagai berikut :

"Sebenanrnya kebiri itu ada yang dipotong langsung sebagai bentuk sanksi pada pelaku zina. Tapi kalau sekarang kan mungkin sudah ada cara lain. Misal suntik yang membuat laki-laki tidak punya keinginan lagi untuk berhubungan seksual. Nah mungkin seperti ini yang dimaksud. Hanya saja fakta vasektomi kan beda ya. Karena atas kemauan sendiri, bukan sebagai sanksi. Pilihan pemakai. Tapi tetap saja harus di detaili faktanya dulu bagaimana" (UAF, 46 th)

Meski demikian, MUI sendiri memang telah mengeluarkan tulisan terkait kehalalan Vasektomi.

Dari hasil penelitian ini terlihat bahwa operasi kontrasepsi vasektomi yang bersifat permanen inilah yang diduga menjadi alasan utama mengapa pria yang ingin melakukannya harus berpikir lagi. Sebab, yang melakukan vasektomi sudah benar-benar yakin tidak ingin memiliki anak lagi dan tidak akan berubah pikiran.

Sebagaimana teorinya, vasektomi merupakan operasi yang menghambat saluran sperma sehingga memungkinkan untuk tidak bisa melakukan pembuahan. Dibutuhkan upaya berupa pendekatan berbasis komunitas, membentuk kemitraan bersama tokoh masyarakat, serta promosi kesehatan terkait jenis kontrasepsi ini.(7)

\section{SIMPULAN}

Berdasarkan hasil penelitian di atas dapat disimpulkan sebagai berikut :

1. Vasektomi/KB Pria masih kurang diperkenalkan di tengah-tengah masyarakat.

2. Hubungan aspek budaya yang mempengaruhi persepsi pria yang telah menikah terkait masalah vasektomi dipengaruhi edukasi yang kurang digencarkan.

3. Dari sisi budaya, vasektomi sebagai program untuk menjaga jarak kelahiran dipandang sama dengan program KB yang dijalani kaum lbu.

4. Risiko vasektomi yang bersifat permanen menimbulkan ketakutan tersendiri pada para suami untuk menjalani vasektomi. 
Jurnal Ilmiah Mahasiswa Kesehatan Masyarakat

1. Perlu upaya promosi sebagai langkah edukasi mengenai vasektomi di tengah-tengah masyarakat.

2. Edukasi kesehatan dapat melibatkan tokoh masyarakat, tokoh agama dan tokoh adat.

\section{DAFTAR PUSTAKA}

1. Kependudukan B, Keluarga DAN, Nasional B. KINER JA BKKBN 2018.

2. Sesotyorini P. Non Vasektomi. 2018;20(2):8192.

3. Penerjemah:, Suryadarma MFHS. Antropologi kesehatan / George M. Foster; Perpustakaan Indonesia, UI Press, 2008.

4. Notoadmodjo S. Promosi Kesehatan, Teori dan Aplikasi, Rineka Cipta, Jakarta, 2008.

5. Saldaña MBM• AMH• J, University AS. Qualitative Data Analysis, Data Analysis A Methods Sourcebook Edition3.

6. Ab, Syamsuddin,Dr. Hj. Indirawaty, S. Pd., S. Kep., NS., M. Kes. Sumarmi, S. Kep., NS. M. Penerapan Dasar-dasar Antropologi Kesehatan, Penerbit Erka CV. Rumahkayu Pustaka Utama, 2017.

7. Lusiana El Sinta Bustami, S.ST. M.Keb Aldina Ayunda Insani BMK, dr. Detty Iryani, M.Kes, M.Pd.Ked. AlF Yulizawati, S.ST MK, KEB. Kebidanan Komunitas, buatbuku.com, 2017. 